\title{
Incidence and risk factors for adverse events during anesthesiologist-led sedation or anesthesia for diagnostic imaging in children: a prospective, observational cohort study
}

Tachawan Jirativanont, Kattiya Manomayangkul, Yuthana Udomphorn, Bencharatana Yokubol, Amorn Saguansab, Kanitha Kraiprasit, Wiruntri Punchuklang Department of Anesthesiology, Faculty of Medicine, Siriraj Hospital, Mahidol University, Bangkok 10700, Thailand

Background: Pediatric sedation for diagnostic radiological procedures remains the mainstay for adequate imaging quality.

Objectives: To clarify the risk of adverse events during anesthesiologist-led sedation or anesthesia for diagnostic radiological procedures in children in order to improve quality of care.

Methods: We enrolled children aged $<15$ years given sedation or anesthesia by an anesthesiologist and scheduled for computed tomography, magnetic resonance imaging, or nuclear medicine imaging November 2010-September 2014. We recorded adverse events occurring in the first $24 \mathrm{~h}$.

Results: Of 1,042 patients enrolled, adverse events were recorded in 254 (24.4\%, 95\% confidence interval [CI] 21.9 to 27.1$)$. Adverse respiratory events occurred in 31 (3.0\%), cardiovascular events in 7 (0.7\%), sedation was prolonged in 165 (15.8\%), there was one case of contrast allergy $(0.01 \%)$, and there were 50 other minor complications (4.9\%). Of the respiratory complications, there were 14 of airway obstruction (1.3\%), 2 of apnea $(0.2 \%), 14$ of oxygen desaturation (1.3\%), and one of laryngospasm $(0.01 \%)$. There were no life threatening complications or consequences. Age $<1$ year (adjusted odds ratio [adjusted OR] 2.5, 95\% CI 1.2 to 5.3) and American Society of Anesthesiologists (ASA) physical status classification 2 and 3 (adjusted OR 4.6, 95\% CI 1.1 to 19.8, and adjusted OR 6.3, 95\% CI 1.3 to 30.9, respectively) were risk factors for respiratory complications. Conclusions: Adverse events were common during sedation or anesthesia, but no life threatening or sentinel events occurred under experienced supervision. Caution should be exercised in children $<1$ year or with an ASA classification $>1$.

Keywords: Adverse event, anesthesiologist, pediatric radiological sedation, risk factor

Computed tomography (CT), magnetic resonance imaging (MRI), and nuclear medicine imaging have become routine in diagnostic clinical practice. They are often noninvasive and not painful; however, patients need to be able to lie still for the duration of image acquisition. This may be particularly challenging in children. Techniques such as sleep deprivation [1], feed and sleep/wrap [2], play therapy [3], administration of melatonin [4], and parental involvement can make some children more cooperative, but sedation remains the most reliable means of ensuring that children are motionless for

Correspondence to: Tachawan Jirativanont, Department of Anesthesiology, Faculty of Medicine, Siriraj Hospital, Mahidol University, Bangkok 10700, Thailand. E-mail: Tachawan.jir@ mahidol.ac.th their diagnostic imaging. However, sedation is not free of risk.

Sedation is defined as "a continuum of the state of consciousness ranging from minimal sedation (anxiolysis) to general anesthesia” [5]. Incremental doses of sedative-hypnotic drugs increase the depth of sedation, but also the risk of an adverse event. Younger children, those with developmental delay, and those requiring more invasive investigations need to be sedated more deeply [6]. Furthermore, substantial clinical experience is needed to monitor and maintain the depth of sedation at the desired level [7].

Guidelines for the safe administration of sedatives to children have been developed in response to the increasing need for procedures performed outside the operating theater [5, 8-10], and have been shown to be effective [11]. These guidelines acknowledge 
and seek to address the increased risks of potentially life-threatening adverse events in these clinical scenarios, even in experienced hands. The Pediatric Sedation Research Consortium has reported one cardiac arrest in a cohort of 30,037 children receiving sedation [12], and 2 in a later cohort of 49,836 children sedated with propofol [13], but with no deaths. Nevertheless, deaths do still occur and continue to be reported [14].

A wide variety of professions and physicians of different specialties may administer pediatric sedation, depending on institutional and national norms. In our hospital, anesthesiologists work as part of a multidisciplinary diagnostic imaging team to provide pediatric sedation. To improve the quality of care, we sought to establish the incidence of complications in children undergoing diagnostic imaging during sedation administered by anesthesiologists and in the first $24 \mathrm{~h}$ thereafter, and also to identify the risk factors for adverse events.

\section{Methods}

This observational cohort study was conducted at Siriraj Hospital, Mahidol University, a tertiary medical center in Bangkok, Thailand. We received approval from the Siriraj Institutional Review Board (certificate of approval No. Si 642/2010) and our study complied with the ethical standards stated in the contemporary Declaration of Helsinki, CIMOS guidelines, and the International Conference on Harmonization of Good Clinical Practice. We prospectively enrolled all children under 15 years old scheduled for CT, MRI, or nuclear medicine studies under sedation and under the care of an anesthesiologist into our study. Written consent was obtained for data collection and a telephone follow-up after $24 \mathrm{~h}$ from parents or guardians, and the children countersigned consent forms to give their ascent if they had capacity to understand the study. We excluded emergency cases, or where patients or their care takers declined to give consent for data collection or telephone follow-up.

Sedation was arranged by each patient's responsible physician by referral to the anesthesia team. Anesthesia care was based on American Academy of Pediatrics recommendations [8]. Presedation assessment was performed by the anesthesiologist in charge on the day before or on the day of the procedure. All children fasted before the procedure for at least $6 \mathrm{~h}$ for food, $4 \mathrm{~h}$ for breast milk and $2 \mathrm{~h}$ for clear liquid including water. Many children were admitted before or after the procedure as a result of their underlying condition; however, cases of patients admitted solely because of the complications of sedation or anesthesia were recorded. Each patient was attended to throughout by a board-certified anesthesiologist, sometimes assisted by a resident, nurse anesthetist, or student nurse anesthetist.

Intravenous access was obtained in all cases. Routine monitoring comprised pulse oximetry and noninvasive blood pressure recording: an electrocardiogram was monitored if the procedure was expected to take more than 10 minutes and capnography was used for cases performed under general anesthesia. After the procedure, patients were observed in the postanesthesia care unit (PACU) by PACU staff, and were discharged either to the ward or home when discharge criteria were met.

We collected demographic data such as age and sex, and clinical data such as diagnosis, fasting time, American Society of Anesthesiologists (ASA) physical status classification, type of procedure, drugs administered, and duration of sedation. The primary outcome of this study was the incidence of any adverse event during the procedure or in the subsequent $24 \mathrm{~h}$, by which time anesthetic drugs would have been eliminated.

Adverse events were recorded if they occurred during the procedure, in the PACU, or after discharge from the PACU. Parents were educated to identify possible complications and were asked to describe any abnormal symptoms reported by their children at a telephone interview, which was conducted even if the child had not left hospital. For those who could not be contacted at $24 \mathrm{~h}$, a second attempt was made to do so at $48 \mathrm{~h}$. Those who could still not be contacted were recorded as being lost to follow-up and data identified as missing.

Adverse events were categorized as those affecting the respiratory system, cardiovascular system, quality of sedation, and others (Table 1). Respiratory adverse events included airway obstruction, apnea, desaturation, laryngospasm, and pulmonary aspiration. Cardiovascular adverse events included cardiac arrest, hypotension, and cardiac arrhythmia. Quality of sedation was defined as adverse if it was inadequate or prolonged. Drug errors and allergic reactions were also recorded. We also recorded other complications reported by parents. 
Table 1. Definition of an adverse event used in this study

\begin{tabular}{|c|c|}
\hline Adverse Event & Definition \\
\hline Airway obstruction & Obstruction of the upper airway necessitating airway management \\
\hline Apnea & Cessation of breathing for $>15$ seconds \\
\hline Desaturation & Reduction in peripheral oxygen saturation $\geq 10 \%$ from baseline \\
\hline Laryngospasm & Chest movement, but no airflow \\
\hline Pulmonary aspiration & Evidence of gastric contents in the airway with desaturation \\
\hline Cardiac arrest & Lack of cardiac output \\
\hline Hypotension & Systolic blood pressure $\leq 20 \%$ of baseline \\
\hline Cardiac arrhythmia & $\begin{array}{l}\text { Heartbeat variation from the normal rhythm, including bradycardia (heart rate } \\
<100 \text { beats/min in a child less than } 1 \text { year old, }<80 \text { beats/min in a child }>1 \text { year old } \\
\text { to } 8 \text { years old, }<60 \text { beat/min in a child }>8 \text { years old to } 15 \text { years old) }\end{array}$ \\
\hline Prolonged sedation & Sedation continuing for $>30$ min after the end of the procedure \\
\hline Inadequate sedation & $\begin{array}{l}\text { Difficulty in completing the procedure because of the child's anxiety or inability } \\
\text { to remain still }\end{array}$ \\
\hline Drug error & Incorrect medication, route, or dosage of drug administration \\
\hline Drug allergy & $\begin{array}{l}\text { An immunological response to medication with proved allergen or improved in } \\
\text { allergic symptoms after antihistamine treatment }\end{array}$ \\
\hline Others & $\begin{array}{l}\text { Other complications that do not affect the cardiovascular system, for example, } \\
\text { nausea, or vomiting, or both; or change in behavior }\end{array}$ \\
\hline
\end{tabular}

\section{Statistical analyses}

A sample size of at least 1,020 was calculated on the basis of an expected incidence of respiratory complications of $5.5 \% \pm 1.4 \%$, based on a previous study [15]. The chi-squared test was used to compare categorical data and multivariate logistic regression analysis undertaken to establish predictors of adverse events expressed as adjusted odds ratios (adjusted OR) and 95\% confidence intervals (CI). All analyses were conducted using SPSS for Windows software, version 16.

\section{Results}

Data were collected between November 2010 and September 2014, but data collected between September 2011 and March 2012 were lost in catastrophic flooding that affected Thailand. The details of 1,250 cases were recorded, but 48 patients were excluded because parents could not be reached for follow-up and other data were incomplete in 160 cases, 1,042 patients were included in the analysis. The age, sex, ASA physical status, type of imaging procedure, and type of anesthesia are presented in Table 2.

Every child had fasted, for a mean duration of $7.2 \pm 1.8 \mathrm{~h}$. The minimum fasting time was $2 \mathrm{~h}$ for water and maximum $24 \mathrm{~h}$ for food. Sedation was administered to 710 children (68.1\%) and general anesthesia to 332 (31.9\%). The primary underlying diseases and the drugs used for sedation or general anesthesia are also shown in Table 2. More than one drug may have been used in a case.

Adverse events within $24 \mathrm{~h}$ of the procedure were recorded in 254 cases (24.4\%, 95\% CI 21.9 to 27.1 ); 31 affected the respiratory system (2.9\%), 7 the cardiovascular system (0.7\%), 165 (15.8\%) had prolonged sedation, there was one case of $(0.1 \%)$ contrast medium allergy, and 50 patients (4.9\%) had other complications such as nausea, vomiting, dizziness, or anxiety (Table 3).

Of the respiratory complications recorded, 14 were airway obstruction (1.3\%), 2 were apnea $(0.2 \%)$, 14 were oxygen desaturation (1.3\%), and 1 was laryngospasm (0.1\%). There was also one incident of regurgitation of gastric contents, but without pulmonary aspiration. All complications were treated promptly by repositioning, introduction of an airway device, bagvalve-mask ventilation or suctioning of secretions. There were no long-term sequelae. Logistic regression analysis identified that age $<1$ year, and ASA classification 2 and 3 significantly predicted respiratory adverse events (Table 4).

Five children developed hypotension (0.5\%) and two developed bradycardia $(0.2 \%)$, which were addressed by intravenous fluid management resuscitation and vasopressors as appropriate. One 
hundred and sixty-five children (15.8\%) had prolonged sedation or took more than 30 minutes to wake up; the risk was increased in cases in which $>2$ drugs were used as shown in Table 5.

There was no incidence of inadequate sedation. Miscellaneous complications included one case of a leaking intravenous catheter $(0.1 \%), 33$ of nausea and vomiting (3.2\%), 3 of rash ( $0.3 \%), 8$ of pyrexia and cough ( $0.8 \%), 3$ of dizziness ( $0.3 \%$ ) and 2 of agitation $(0.2 \%)$. Most miscellaneous complications occurred after discharge from the PACU and were reported by parents, except the case of the leaking intravenous catheter and 4 of the cases of nausea and vomiting. No children were admitted to hospital or required additional medical care as a result of any of the complications recorded.

Table 2. Demographic and clinical characteristics of children in the cohort $(n=1,042)$

\begin{tabular}{|c|c|}
\hline Characteristic & Value \\
\hline Age $(y)^{1}$ & $3.3 \pm 3.0$ \\
\hline \multicolumn{2}{|l|}{ Sex } \\
\hline Male & $615(59.0 \%)$ \\
\hline Female & $427(41.0 \%)$ \\
\hline \multicolumn{2}{|c|}{ American Society of Anesthesiologists classification } \\
\hline 1 & $269(25.8 \%)$ \\
\hline 2 & $633(60.7 \%)$ \\
\hline 3 & $140(13.4 \%)$ \\
\hline \multicolumn{2}{|c|}{ Underlying disease categorized by system } \\
\hline Neurological system & $393(37.7 \%)$ \\
\hline Genitourinary system & $220(21.1 \%)$ \\
\hline Gastrointestinal system & $150(14.4 \%)$ \\
\hline Eye & $70(6.7 \%)$ \\
\hline Musculoskeletal system & $69(6.6 \%)$ \\
\hline Respiratory system & $41(3.9 \%)$ \\
\hline Hematological system & $39(3.7 \%)$ \\
\hline Ear, nose, or throat & $34(3.3 \%)$ \\
\hline Cardiac system & $13(1.2 \%)$ \\
\hline Endocrine system & $8(0.8 \%)$ \\
\hline Skin & $5(0.5 \%)$ \\
\hline \multicolumn{2}{|l|}{ Imaging procedure } \\
\hline Computed tomography & $267(25.6 \%)$ \\
\hline Magnetic resonance imaging & $469(45.0 \%)$ \\
\hline Nuclear medicine & $306(29.4 \%)$ \\
\hline \multicolumn{2}{|l|}{ Type of anesthesia } \\
\hline Sedation & $710(68.1 \%)$ \\
\hline General anesthesia & $332(31.9 \%)$ \\
\hline \multicolumn{2}{|l|}{ Drug(s) used ${ }^{2}$} \\
\hline Midazolam & $970(93.1 \%)$ \\
\hline Propofol & $818(78.5 \%)$ \\
\hline Ketamine & $666(63.9 \%)$ \\
\hline Sevoflurane & $374(35.9 \%)$ \\
\hline Opioid & $15(1.4 \%)$ \\
\hline Thiopental & $14(1.3 \%)$ \\
\hline Chloral hydrate & $4(0.4 \%)$ \\
\hline
\end{tabular}

${ }^{1}$ Mean \pm standard deviation, ${ }^{2}$ More than one drug may have been used in each patient 
Table 3. Incidence of adverse events categorized by system and time of event

\begin{tabular}{|c|c|c|c|}
\hline \multirow[t]{2}{*}{ Complication } & \multicolumn{3}{|c|}{ Number (\%) } \\
\hline & $\begin{array}{l}\text { During procedure } \\
\quad(n=35)\end{array}$ & $\begin{array}{l}\text { PACU } \\
(n=174)\end{array}$ & $\begin{array}{c}\text { Post-PACU } \\
(n=45)\end{array}$ \\
\hline \multicolumn{4}{|l|}{ Respiratory complication $(\mathrm{n}=31)$} \\
\hline Airway obstruction $(\mathrm{n}=14)$ & $13(1.2 \%)$ & $1(0.1 \%)$ & 0 \\
\hline Apnea $(n=2)$ & $2(0.2 \%)$ & 0 & 0 \\
\hline Desaturation $(n=14)$ & $11(1.0 \%)$ & $3(0.3 \%)$ & 0 \\
\hline Laryngospasm (n=1) & $1(0.1 \%)$ & 0 & 0 \\
\hline \multicolumn{4}{|c|}{ Cardiovascular complications $(\mathbf{n}=7)$} \\
\hline Hypotension $(\mathrm{n}=5)$ & $4(0.4 \%)$ & $1(0.1 \%)$ & 0 \\
\hline Cardiac arrhythmia $(\mathrm{n}=2)$ & $2(0.2 \%)$ & 0 & 0 \\
\hline \multicolumn{4}{|l|}{ Quality of sedation $(n=165)$} \\
\hline Prolonged sedation $(\mathrm{n}=165)$ & 0 & $165(15.8 \%)$ & 0 \\
\hline Drug allergy $(n=1)$ & $1(0.1 \%)$ & 0 & 0 \\
\hline Others $(n=50)$ & $1(0.1 \%)$ & $4(0.4 \%)$ & $45(4.3 \%)$ \\
\hline
\end{tabular}

PACU = postanesthesia care unit

Table 4. Predictors of respiratory adverse events

\begin{tabular}{llcc}
\hline Variable & Numbers & $\begin{array}{c}\text { Crude odds ratio (95\% } \\
\text { confidence intervals) }\end{array}$ & $\begin{array}{c}\text { Adjusted odds ratio* } \\
\text { (95\% confidence intervals) }\end{array}$ \\
\hline $\begin{array}{l}\text { Age } \\
>1 \mathrm{y}\end{array}$ & $12 / 648$ & 1.0 & - \\
$\quad \leq 1 \mathrm{y}$ & $19 / 394$ & $2.7(1.3,5.6)$ & $2.5(1.2,5.3)$ \\
ASA classification & $2 / 269$ & 1.0 & 1 \\
1 & $22 / 633$ & $4.8(1.1,20.6)$ & $-1.6(1.1,19.8)$ \\
2 & $7 / 140$ & $7.0(1.4,34.3)$ & - \\
3 & & & - \\
Number of drugs used & $1 / 54$ & 1.0 & - \\
1 & $13 / 382$ & $1.8(0.2,14.6)$ & - \\
2 & $17 / 606$ & $1.5(0.2,11.7)$ & - \\
$\quad \geq 3$ & & & - \\
Choice of technique & $22 / 710$ & 1.0 & - \\
Sedation & $9 / 332$ & $0.87(0.4,1.9)$ & - \\
$\quad$ General anesthesia & $3 / 134$ & $2.7(0.2,2.4)$ & \\
Pulmonary disease & $3 / 42$ & & \\
Difficult airway & & &
\end{tabular}

Adjusted odds ratio by logistic regression, ASA = American Society of Anesthesiologists 
Table 5. Predictors of prolonged sedation

\begin{tabular}{|c|c|c|c|}
\hline Variable & Numbers & $\begin{array}{l}\text { Crude odds ratio ( } 95 \% \\
\text { confidence intervals) }\end{array}$ & $\begin{array}{c}\text { Adjusted odds ratio* } \\
\text { (95\% confidence intervals) }\end{array}$ \\
\hline \multicolumn{4}{|l|}{ Age } \\
\hline$>1 \mathrm{y}$ & $113 / 648$ & 1.0 & - \\
\hline$\leq 1 \mathrm{y}$ & $53 / 394$ & $0.7(0.5,1.1)$ & - \\
\hline \multicolumn{4}{|l|}{ ASA classification } \\
\hline 1 & $41 / 269$ & 1.0 & - \\
\hline 2 & $103 / 633$ & $1.1(0.7,1.6)$ & - \\
\hline 3 & $22 / 140$ & $1.0(0.5,1.8)$ & - \\
\hline \multicolumn{4}{|l|}{ Number of drugs used } \\
\hline 1 & $1 / 54$ & 1.0 & - \\
\hline 2 & $34 / 382$ & $5.2(0.7,38.6)$ & $5.3(0.7,39.8)$ \\
\hline$\geq 3$ & $131 / 606$ & $14.6(2.0,106.7)$ & $13.5(1.8,99.3)$ \\
\hline \multicolumn{4}{|l|}{ Choice of technique } \\
\hline Sedation & $93 / 710$ & 1 & - \\
\hline General anesthesia & 73/332 & $1.9(1.3,2.6)$ & $1.3(0.9,1.8)$ \\
\hline
\end{tabular}

*odds ratio adjusted by logistic regression

\section{Discussion}

There is wide variation in the reported incidence of adverse events complicating sedation in children. This can largely be explained by differences in definitions [16], standards of care, the provider of sedation [15, 17-19], and sedation technique [20-24]. Previous cohorts have also included children undergoing painful or nonpainful procedures, and those involving the airway such as dental surgery or upper airway endoscopy, all of which require a wide variety of techniques, drugs and doses [25]. Most safety data have not been reported from the perspective of the anesthesiologist.

We focused on adverse events occurring in children undergoing anesthesiologist-led sedation for nonpainful imaging investigations during or within the first $24 \mathrm{~h}$ of the procedure. We excluded emergencies, because these may have been overseen by a resident or nurse anesthetist. All patients were subjected to a standard fasting protocol and monitored with at least a pulse oximeter. Just under a quarter (252 of 1,042 cases, $24.2 \%$ ) experienced complications within the first $24 \mathrm{~h}$, but none was life threatening. Almost $4 \%$ experienced cardiopulmonary complications, most of which occurred during the procedure and were corrected by immediate action from the anesthesiologist. There were no cardiopulmonary complications after discharge from the PACU, but there were a few cases of nausea and vomiting, dizziness, and agitation. Although some parents reported rash and fever with cough, it was not possible to establish whether these were complications of sedation, or not.

The incidence of cardiorespiratory adverse events in our study was comparable to or slightly less than other reports of sedation for nonpainful radiological procedures [21, 26]. Malviya et al. reported an incidence of inadequate sedation of $16 \%$ in their cohort, but prolonged sedation in $0.1 \%$, a situation that was almost contrary of our findings, and can likely be explained by variation in anesthesiologists' practice.

The literature describes a number of factors contributing to adverse events; those related to healthcare systems, the characteristics of patients, depth of sedation, and drugs used. Cote et al. reviewed 95 cases of serious adverse events encountered during pediatric sedation: 51 resulted in death and 9 in permanent neurological damage. Inadequate and inconsistent physiological monitoring, inadequate resuscitation and performing cases outside the hospital environment were the major factors associated with poor outcome [27]. These findings are consistent with those of Lee et al., who collated public and media reports of deaths of children during sedation for dental procedures and found that risks were substantially increased in the office setting, with the exception of an experienced team working in a dedicated center [14], the outcomes of which are reportedly comparable to hospital-based practice [28]. The specialty or specialties that provide sedation for 
children is highly dependent on the healthcare provider, and seems likely to influence the incidence of complications. Lee et al. found that in the pediatric dental setting, morbidity and mortality occurred more often when the dentist was responsible for sedation [14], implying that when sedation is provided by the operator, the patient's vital signs might be neglected. However, Couloures et al. were unable to demonstrate differences in complication rates between providers in an analysis of major complications recorded in more than 100,000 cases [17]. In this study, we focused solely on anesthesiologists' performance, and found no serious adverse events among 254 complication reports, although the administration of more than two drugs was associated with delayed emergence. The ability to anticipate and detect adverse events, and treat them promptly and effectively when they arise, is essential.

Patient characteristics also influence the incidence of adverse events. Age $<6$ months [13] or $<1$ year [15], ASA classification more than 2 [13, 15, $21,24]$, comorbid respiratory disease [20, 24] or intellectual disabilities [29] are reportedly predictors of adverse events. We found that age $<1$ year and ASA classification $>1$ were risk factors for cardiopulmonary complications, which may arise as a consequence of differences in the anatomy and physiology of the infant airway [30], and the reduced cardiopulmonary reserve in sick children. A prominent occiput, short neck, and large tongue make the infant prone to airway obstruction, and greater oxygen consumption and lower functional residual capacity result in rapid desaturation during apnea. Our findings highlight the importance of ensuring that these patients are sedated or anesthetized by experienced pediatric anesthesiologists.

Sedation is a continuum of the level of consciousness: deep sedation suppresses cardiopulmonary function. In minimal (anxiolysis) and moderate (conscious) sedation, when patients can respond purposefully to verbal or tactile stimulation, it is rare to need airway adjuncts [5]. These levels of sedation might not be able to prevent uncooperative children from moving during imaging. In deep sedation, patients will respond purposefully to painful stimuli, and airway intervention may be needed. We generally manage newborns by feeding and wrapping, and use play therapy or parental involvement in older, more cooperative children. In younger or uncooperative children, deep sedation is usually required, but the boundary between deep sedation and anesthesia can be difficult to maintain, and airway and hemodynamic management may become necessary. Even in deep sedation it can be very difficult to keep patients still, especially during painful procedures. The term "minimal anesthesia" has been proposed [31]. This technique requires higher doses of sedative drugs at almost the anesthetic dose and administration of supplemental oxygen, but no advanced airway management is used. In our practice, we judged that some of our patients could be described as receiving "minimal anesthesia". This likely explains the 3\% incidence of respiratory complications in our cohort, and underlines the importance of correct patient positioning and judicious titration of sedative drugs. Deeply sedated patients might have had undetected alveolar hypoventilation, because we only used capnography in those undergoing general anesthesia [32].

The reasons for choosing general anesthesia have not been shown in this report. However, in our practice, we considered general anesthesia particularly in high risk patients with airway abnormalities or longer procedures such as MRI, by titrating intravenous propofol infusion or inhaled sevoflurane, or both, to achieve spontaneous ventilation with minimal support.

A wide variety of sedative drugs are in routine use for pediatric sedation. Midazolam was used most frequently in this study, but often in combination with others. Propofol has been proposed as an ideal agent for nonpainful procedural sedation [33] because of its rapid onset and offset — although this must be weighed against its profound respiratory and cardiovascular depressant effects. Propofol should only be used by experienced physicians competent in airway management. We tended to use propofol in longer procedures requiring deep sedation, and ketamine for short procedures or as an adjunct to others for longer procedures. Ketamine is popular as a sedative and analgesic agent in emergency medicine [9], providing dissociative anesthesia while maintaining respiratory and hemodynamic function, albeit at the expense of abnormal movements [34], delayed emergence compared with propofol [35] and agitation, nausea and vomiting during recovery $[9,36]$. We mostly used sevoflurane when intravenous access was difficult, and for general anesthesia. We are unable to draw any firm conclusions about the influence of individual drugs on the adverse events recorded, because of the use of different doses and combinations. 
Our study has some limitations. First, the definition of an adverse event might have influenced our findings. For example, we used a definition of desaturation of a decrease in peripheral oxygen saturation $<10 \%$ from baseline, which would not be tolerated by most anesthesiologists without intervention. An intervention-driven definition might be more appropriate [37]. Another example is prolonged sedation: we chose the definition of continuing sedation $>30$ minutes to compare our findings with another study [21]. We also expected the patient to wake up within a few minutes of completion of the procedure, so our finding that almost $16 \%$ experienced prolonged sedation was surprising. The time taken for readiness for discharge may have been a better reflection of the quality of sedation. In terms of oversedation, we use prolonged sedation instead of oversedation, which includes both prolonged sedation and excessive depth of sedation, for the reason that we could not really assess depth of sedation at all times of the procedure, especially in patients who undergo MRI. Prolonged sedation might refer to the number of oversedated patients in this study. Another limitation is that our overall assessment of risk includes the risk from both general anesthesia and sedation, which may differ in nature and extent between each group. For example, general anesthesia may have had fewer respiratory complications, but required a longer time for recovery. We chose to include both sedation and general anesthesia in our analysis to establish the overall risk of our service.

The use of a telephone interview after discharge from PACU led to 48 cases being lost to follow-up, and parents may have missed or misinterpreted some adverse events. A verified instrument should be used to measure behavioral outcomes more precisely.

\section{Conclusions}

We found that adverse events were recorded in almost $25 \%$ of sedation or anesthesia episodes for pediatric diagnostic imaging procedures within the first $24 \mathrm{~h}$. Prompt detection and effective treatment played an important role in preventing any major adverse events. Age $<1$ year and ASA classification $>1$ predicted respiratory adverse events.

\section{Acknowledgment}

The authors thank Mr. Suthipol Udompanturak, Division of Clinical epidemiology, Department of Research and Development Faculty of Medicine,
Siriraj Hospital, Mahidol University, for statistical advice, and Miss Nichapat Sookri, research assistant, for the data collection. This study was supported by Siriraj Research and Development Fund.

\section{Conflict of interest statement}

The authors have no conflicts of interest to declare.

\section{References}

1. Shields CH, Johnson S, Knoll J, Chess C, Goldberg D, Creamer K. Sleep deprivation for pediatric sedated procedures: not worth the effort. Pediatrics. 2004; 113: 1204-8.

2. Mathur AM, Neil JJ, McKinstry RC, Inder TE. Transport, monitoring, and successful brain MR imaging in unsedated neonates. Pediatr Radiol. 2008; 38:260-4.

3. Pressdee D, May L, Eastman E, Grier D. The use of play therapy in the preparation of children undergoing MR imaging. Clin Radiol. 1997; 52:945-7.

4. Sury MR, Fairweather K. The effect of melatonin on sedation of children undergoing magnetic resonance imaging. Br J Anaesth. 2006; 97:220-5.

5. American Society of Anesthesiologists Task Force on Sedation and Analgesia by Non-Anesthesiologists. Practice guidelines for sedation and analgesia by non-anesthesiologists. Anesthesiology. 2002; 96: 1004-17.

6. Maxwell LG, Yaster M. The myth of conscious sedation. Arch Pediatr Adolesc Med. 1996; 150:665-7.

7. Dial S, Silver P, Bock K, Sagy M. Pediatric sedation for procedures titrated to a desired degree of immobility results in unpredictable depth of sedation. Pediatr Emerg Care. 2001; 17:414-20.

8. Cote CJ, Wilson S. Guidelines for monitoring and management of pediatric patients during and after sedation for diagnostic and therapeutic procedures: an update. Pediatrics. 2006; 118:2587-602.

9. Green SM, Roback MG, Kennedy RM, Krauss B. Clinical practice guideline for emergency department ketamine dissociative sedation: 2011 update. Ann Emerg Med. 2011; 57:449-61.

10. American Academy on Pediatrics, American Academy on Pediatric Dentistry. Guideline for monitoring and management of pediatric patients during and after sedation for diagnostic and therapeutic procedures. Pediatr Dent. 2008; 30:143-59.

11. Hoffman GM, Nowakowski R, Troshynski TJ, Berens RJ, Weisman SJ. Risk reduction in pediatric procedural 
sedation by application of an American Academy of Pediatrics/American Society of Anesthesiologists process model. Pediatrics. 2002; 109:236-43.

12. Cravero JP, Blike GT, Beach M, Gallagher SM, Hertzog JH, Havidich JE, et al. Incidence and nature of adverse events during pediatric sedation/anesthesia for procedures outside the operating room: report from the Pediatric Sedation Research Consortium. Pediatrics. 2006; 118:1087-96.

13. Cravero JP, Beach ML, Blike GT, Gallagher SM, Hertzog JH, Pediatric Sedation Research Consortium. The incidence and nature of adverse events during pediatric sedation/anesthesia with propofol for procedures outside the operating room: a report from the Pediatric Sedation Research Consortium. Anesth Analg. 2009; 108:795-804.

14. Lee HH, Milgrom P, Starks H, Burke W. Trends in death associated with pediatric dental sedation and general anesthesia. Paediatr Anaesth. 2013; 23:741-6.

15. Malviya S, Voepel-Lewis T, Tait AR. Adverse events and risk factors associated with the sedation of children by nonanesthesiologists. Anesth Analg. 1997; 85:1207-13.

16. Mason KP, Green SM, Piacevoli Q, International Sedation Task Force. Adverse event reporting tool to standardize the reporting and tracking of adverse events during procedural sedation: a consensus document from the World SIVA International Sedation Task Force. Br J Anaesth. 2012; 108:13-20.

17. Couloures KG, Beach M, Cravero JP, Monroe KK, Hertzog JH. Impact of provider specialty on pediatric procedural sedation complication rates. Pediatrics. 2011; 127:e1154-60.

18. Vargo JJ, Holub JL, Faigel DO, Lieberman DA, Eisen GM. Risk factors for cardiopulmonary events during propofol-mediated upper endoscopy and colonoscopy. Aliment Pharmacol Ther. 2006; 24:955-63.

19. Gozal D, Drenger B, Levin PD, Kadari A, Gozal Y. A pediatric sedation/anesthesia program with dedicated care by anesthesiologists and nurses for procedures outside the operating room. J Pediatr. 2004; 145:47-52.

20. Sanborn PA, Michna E, Zurakowski D, Burrows PE, Fontaine PJ, Connor L, et al. Adverse cardiovascular and respiratory events during sedation of pediatric patients for imaging examinations. Radiology. 2005; 237:288-94.

21. Malviya S, Voepel-Lewis T, Eldevik OP, Rockwell DT, Wong JH, Tait AR. Sedation and general anaesthesia in children undergoing MRI and CT: adverse events and outcomes. Br J Anaesth. 2000; 84:743-8.
22. Green SM, Roback MG, Krauss B, Brown L, McGlone RG, Agrawal D, et al. Predictors of airway and respiratory adverse events with ketamine sedation in the emergency department: an individual-patient data meta-analysis of 8,282 children. Ann Emerg Med. 2009; 54: 158-68 e1-4.

23. Roback MG, Wathen JE, Bajaj L, Bothner JP. Adverse events associated with procedural sedation and analgesia in a pediatric emergency department: a comparison of common parenteral drugs. Acad Emerg Med. 2005; 12:508-13.

24. Kamat PP, McCracken CE, Gillespie SE, Fortenberry JD, Stockwell JA, Cravero JP, et al. Pediatric critical care physician-administered procedural sedation using propofol: a report from the pediatric sedation research consortium database. Ped Crit Care Med. 2015; 16:11-20.

25. Metzner J, Domino KB. Risks of anesthesia or sedation outside the operating room: the role of the anesthesia care provider. Curr Opin Anaesthesiol. 2010; 23:523-31.

26. Srinivasan M, Turmelle M, Depalma LM, Mao J, Carlson DW. Procedural sedation for diagnostic imaging in children by pediatric hospitalists using propofol: analysis of the nature, frequency, and predictors of adverse events and interventions. J Pediatr. 2012; 160:801-6 e1.

27. Cote CJ, Notterman DA, Karl HW, Weinberg JA, McCloskey C. Adverse sedation events in pediatrics: a critical incident analysis of contributing factors. Pediatrics. 2000; 105:805-14.

28. Emrath ET, Stockwell JA, McCracken CE, Simon HK, Kamat PP. Provision of deep procedural sedation by a pediatric sedation team at a freestanding imaging center. Pediatr Radiol. 2014; 44:1020-5.

29. Kannikeswaran N, Mahajan PV, Sethuraman U, Groebe A, Chen X. Sedation medication received and adverse events related to sedation for brain MRI in children with and without developmental disabilities. Paediatr Anaesth. 2009; 19:250-6.

30. Harless J, Ramaiah R, Bhananker SM. Pediatric airway management. Int J Crit Illn Inj Sci. 2014; 4:65-70.

31. Sury MR, Harker H, Begent J, Chong WK. The management of infants and children for painless imaging. Clin Radiol. 2005; 60:731-41.

32. Lightdale JR, Goldmann DA, Feldman HA, Newburg AR, DiNardo JA, Fox VL. Microstream capnography improves patient monitoring during moderate sedation: a randomized, controlled trial. Pediatrics. 2006; 117: e1170-8.

33. Cravero JP, Blike GT. Review of pediatric sedation. 
Anesth Analg. 2004; 99:1355-64.

34. White PF, Way WL, Trevor AJ. Ketamine-its pharmacology and therapeutic uses. Anesthesiology. 1982; 56:119-36.

35. Vardi A, Salem Y, Padeh S, Paret G, Barzilay Z. Is propofol safe for procedural sedation in children? A prospective evaluation of propofol versus ketamine in pediatric critical care. Crit Care Med. 2002; 30: 1231-6.

36. Green SM, Roback MG, Krauss B, Brown L, McGlone RG, Agrawal D, et al. Predictors of emesis and recovery agitation with emergency department ketamine sedation: an individual-patient data metaanalysis of 8,282 children. Ann Emerg Med. 2009; 54: 171-80 e1-4.

37. Bhatt M, Kennedy RM, Osmond MH, Krauss B, McAllister JD, Ansermino JM, et al. Consensus-based recommendations for standardizing terminology and reporting adverse events for emergency department procedural sedation and analgesia in children. Ann Emerg Med. 2009; 53:426-35 e4. 